\title{
Twitching motility among pathogenic Xylella fastidiosa isolates and the influence of bovine serum albumin on twitching-dependent colony fringe morphology
}

\author{
Cheryl D. Galvani, Yaxin Li, Thomas J. Burr \& Harvey C. Hoch \\ Department of Plant Pathology, Cornell University-New York State Agricultural Experiment Station, Geneva, NY, USA
}

\begin{abstract}
Correspondence: Harvey C. Hoch, Department of Plant Pathology, Cornell University-New York State Agricultural Experiment Station, Geneva, NY 14456 USA. Tel.: +1 315787 2332; fax: +1 315787 2389; e-mail: hch1@cornell.edu
\end{abstract}

Received 11 September 2006; revised 8 November 2006; accepted 21 November 2006. First published online 8 January 2007.

DOI:10.1111/j.1574-6968.2007.00601.x

Editor: David Clarke

Keywords

Pierce's disease; bovine serum albumin; twitching motility; biofilm formation.

\begin{abstract}
Fourteen Xylella fastidiosa isolates from grapevines exhibiting Pierce's disease symptoms in California, Texas, and South Carolina were examined for type IV pilus-mediated twitching motility, a phenotype previously observed in a Temecula isolate from California. All isolates except one from South Carolina (SC 19A97) exhibited colonies with a peripheral fringe on PW agar, a feature indicative of twitching motility; however, when individual cells of SC 19A97 were examined at higher magnifications twitching motility was observed. The presence and width of colony peripheral fringes were related to the amount of bovine serum albumin (BSA) present in the medium; no or low levels of BSA $\left(0-1.8 \mathrm{~g} \mathrm{~L}^{-1}\right)$ permitted development of the widest fringe, whereas higher levels $\left(3.5-6.0 \mathrm{~g} \mathrm{~L}^{-1}\right)$ severely limited, and in many instances prevented, peripheral fringe development. The growth rate of the wild-type Temecula isolate in PW broth with different concentrations of BSA was similar for all tested concentrations of BSA; however, growth was significantly reduced in medium without BSA.
\end{abstract}

\section{Introduction}

Xylella fastidiosa is a gram-negative, nonflagellated bacterium that causes economically important diseases of grape, citrus, peach, almond, coffee, and many other crops (Purcell \& Hopkins, 1996; Simpson et al., 2000; Van Sluys et al., 2003). The bacteria are limited to colonizing the waterconducting xylem vessels of host plants. Such colonization frequently results in obstruction of water and nutrient transport, resulting in disease symptoms and often in plant death. Because $X$. fastidiosa lack flagella, the mechanism by which the bacteria are disseminated through the xylem vascular system has not been well characterized. Recently, it was demonstrated that a Temecula isolate of $X$. fastidiosa that causes Pierce's disease of grapevine developed a 'peripheral fringe' around colonies (Meng et al., 2005) grown on periwinkle wilt (PW) agar (Davis et al., 1981), a trait associated with type IV pilus-mediated twitching motility in other bacterial species (Bradley, 1980; Glessner et al., 1999; Semmler et al., 1999; Liu et al., 2001; Huang et al., 2003). It was further shown that the Temecula isolate could migrate upstream in a fabricated microfluidic chamber against rapidly flowing medium via twitching motility, and that similar migration occurred in planta against the flow of xylem sap (Meng et al., 2005). The observation that the Temecula isolate of $X$. fastidiosa exhibited colony morphologies consistent with twitching motility and that it was capable of migrating against a transpiration stream in xylem vessels led us to ponder why such colony morphologies had not been readily observed in previous reports. The $X$. fastidiosa genome sequence indicates that the bacterium contains at least thirty genes responsible for pilus assembly or function (Simpson et al., 2000; Van Sluys et al., 2003), and earlier descriptions of the genus indicated that some cells had 'fimbria-like fibrils' at the cell poles (Wells et al., 1987). Because the pathogenic Temecula isolate exhibited twitching motility (Meng et al., 2005), it was sought to determine whether this isolate was representative of other wild-type pathogenic $X$. fastidiosa isolates, or whether it was an anomaly, in which case the previous description of twitching motility (Meng et al., 2005) would not be broadly applicable for a role of type IV pili in pathogenesis by this bacterium. Therefore peripheral fringe development in a range of pathogenic $X$. fastidiosa isolates obtained from various grape-growing regions in the United States was assessed. During the course of the survey of the pathogenic isolates, it was discovered that the concentration of bovine serum albumin (BSA) in the medium dramatically 
influenced whether or not a peripheral fringe was associated with the colonies. Thus, the influence of BSA on peripheral fringe development in X. fastidiosa is also reported here.

\section{Materials and methods}

\section{Maintenance and storage of bacterial isolates}

Wild-type X. fastidiosa Temecula (ATCC 700964) and other wild-type isolates were maintained at $28^{\circ} \mathrm{C}$ on $\mathrm{PW}$ agar (Davis et al., 1981) without phenol red and with $3.5 \mathrm{~g} \mathrm{~L}^{-1}$ instead of $6.0 \mathrm{~g} \mathrm{~L}^{-1}$ BSA (Cat. No. A-8918, Sigma, St Louis, MO). It should be noted that following this study, Sigma discontinued production of A-8918 and replaced it with A-7979, which is inferior in supporting the growth of $X$. fastidiosa. A survey of BSA products by various manufacturers revealed that a Gibco product (Cat. No. 15260, Invitrogen, Carlsbad, CA) was equivalent to the original Sigma product for supporting growth. The transposongenerated mutants 6E11 ( fim $^{-}$) and $1 \mathrm{~A} 2$ (pilB ${ }^{-}$) (Meng et al., 2005) were similarly maintained in culture as the Temecula parent, but with $50 \mu \mathrm{g} \mathrm{mL}^{-1}$ kanamycin added to the PW agar. Wild-type isolates of X. fastidiosa, recently isolated from diseased grapevines and with few transfers in in vitro culture, were obtained from California, Texas, and South Carolina (Table 1). Isolates and mutants were stored frozen at $-80^{\circ} \mathrm{C}$ in $\mathrm{PW}$ broth containing $7 \%$ final concentration DMSO (Sigma). Owing to the reported loss of virulence during successive transfers in axenic culture (Hopkins, 1985; de Souza et al., 2003), all wild-type isolates and mutants were handled with fewer than ten serial transfers following retrieval from freezer storage.

\section{Assessment of colony morphology}

Using rounded toothpicks, cells from 5-7-day-old X. fastidiosa cultures were spotted aseptically onto PW agar containing four different BSA concentrations: $0,1.8,3.5$, or $6.0 \mathrm{~g} \mathrm{~L}^{-1}$. Each isolate or mutant was spotted at ten sites on the agar surface of each plate. Cells were grown at $28^{\circ} \mathrm{C}$. Colony morphologies were assessed after 4-7 days with an Olympus SZX12 dissecting microscope using off-center lighting. The experiment was repeated at least three times.

\section{Confirmation of twitching motility}

As above, cells were spotted onto PW agar containing the four BSA concentrations. After 2-3 days of growth, colony morphologies were assessed with an Olympus IMT-2 inverted microscope. For examination of colony twitching, time-lapse digital images of selected individual colony peripheries were captured using METAMORPH image software as previously reported (Meng et al., 2005). Alternatively, for isolates that did not readily exhibit a peripheral fringe around colonies, $X$. fastidiosa cells were spread sparsely onto either the agar surface or onto a sterilized sheet of cellophane overlaid on the agar surface and examined for twitching motility after 1-2 days of growth. The experiment was repeated at least two times.

\section{Growth rate analysis}

Cells from 5-7-day-old PW plates were used to make a cell suspension in PW medium containing four different BSA concentrations: $0,1.8,3.5$, or $6.0 \mathrm{~g} \mathrm{~L}^{-1}$. The initial OD for each cell suspension was adjusted to an absorbance of 0.1 at $600 \mathrm{~nm}$. The cultures were incubated at $28^{\circ} \mathrm{C}$ with

Table 1. Wild-type isolates and mutants of Xylella fastidiosa

\begin{tabular}{lll}
\hline Isolate & Description & Source/(reference, if any) \\
\hline SC 17A54 & Pathogenic wild-type from grapevine & C.J. Chang; South Carolina \\
SC 17A97 & Pathogenic wild-type from grapevine & C.J. Chang; South Carolina \\
SC 18A1 & Pathogenic wild-type from grapevine & C.J. Chang; South Carolina \\
SC 18A4 & Pathogenic wild-type from grapevine & C.J. Chang; South Carolina \\
SC 19A11 & Pathogenic wild-type from grapevine & C.J. Chang; South Carolina \\
SC 19A13 & Pathogenic wild-type from grapevine & C.J. Chang; South Carolina \\
Texas 1.3 & Pathogenic wild-type from grapevine & D. Appel; Texas \\
Texas 3.3 & Pathogenic wild-type from grapevine & D. Appel; Texas \\
Conn Creek & Pathogenic wild-type from grapevine & A. Purcell; California (Hendson et al., 2001) \\
Bakersfield & Pathogenic wild-type from grapevine & A. Purcell; California (Hendson et al., 2001) \\
Medieros & Pathogenic wild-type from grapevine & A. Purcell; California (Hendson et al., 2001) \\
STL & Pathogenic wild-type from grapevine & A. Purcell; California (Hendson et al., 2001) \\
Temecula & Pathogenic wild-type from grapevine & S. Lindow; California (Hendson et al., 2001) \\
Traver & Pathogenic wild-type from grapevine & A. Purcell; California (Hendson et al., 2001) \\
UCLA & Pathogenic wild-type from grapevine & A. Purcell; California (Hendson et al., 2001) \\
Mutants & & \\
1 1A2 & pilB mutant of Temecula; type I pili only; twitch-negative; non-motile & H.C. Hoch, T.J. Burr (Meng et al., 2005) \\
6E11 & fimA mutant of Temecula; type IV pili only; twitch-positive; motile & H.C. Hoch, T.J. Burr (Meng et al., 2005) \\
\hline
\end{tabular}


continuous agitation at 195 r.p.m. Cell density was determined at days $0,1,2,3$, and 4 by measuring OD at $A_{600 ~ n m}$. The experiment was repeated twice.

\section{BSA influence on biofilm development}

A $20 \mu \mathrm{L}$ cell suspension of wild-type $X$. fastidiosa Temecula cells was added to $30 \mathrm{~mL}$ PD2 medium with either $0,1.8,3.5$, or $6.0 \mathrm{~g} \mathrm{~L}^{-1}$ BSA in a $125-\mathrm{mL}$ flask. The experiment was carried out in triplicate for each BSA concentration. Flasks were incubated at $28{ }^{\circ} \mathrm{C}$ with shaking on an orbital shaker (ThermoForma, Marietta, OH) at 100 r.p.m. Following eight and 20 days of growth, the appearance and relative amount of biofilm that formed on the side of the flask was noted. The experiment was repeated twice.

\section{Results and discussion}

Wild-type pathogenic isolates of $X$. fastidiosa from California, South Carolina, and Texas (Table 1) were examined on PW agar for the presence of a peripheral colony fringe, which is indicative of type IV pilus-mediated twitching motility. Eight of the 15 isolates examined are depicted in Fig. 1. All isolates, except SC 17A97 from South Carolina, exhibited a fringe around the periphery of the colony. However, subsequent time-lapse imaging of SC 17A97 cells spread over the agar surface or over cellophane overlaid on agar revealed that they too exhibited twitching motility similar to all the other isolates (not shown). Fringe width varied with the isolate (and with the concentration of BSA as noted below), and was in general consistent with replicated colonies of the same isolate within the same plate as well as in subsequent tests. Several isolates, e.g. Texas 1.3, SC 18A1, SC 17A54, and the 'standard' Temecula as well as the fimA mutant $6 \mathrm{E} 11$ had consistently wider fringes compared with other isolates such as Conn Creek and UCLA (Figs 1 and 2). Higher magnification of the fringe revealed the presence of twitching, motile X. fastidiosa cells, either singly or in aggregates (Fig. 3). Expansion of similar fringe regions and movement of individual bacterial cells has been documented for a number of bacterial species (Bradley, 1980; Glessner et al., 1999; Semmler et al., 1999; Liu et al., 2001; Huang et al., 2003), including $X$. fastidiosa (Meng et al., 2005; also see http://www.nysaes.cornell.edu/pp/faculty/hoch/movies). For comparison purposes, the pilB mutant 1A2, which does not have type IV pili and therefore does not exhibit twitching motility, had a smooth colony margin (Fig. 2).

As noted above, fringe width among the various isolates varied greatly. The reason for this was not discerned, but could be due to any number of factors such as differences in number of type IV pili, length of these pili, extension and retraction rates of the pili, colony expansion rate vs. twitching and fringe expansion rate, etc. In addition, the presence and number of type I pili on these isolates may also influence the twitching motility rate and hence fringe width. Already, it is known that the wild-type Temecula isolate has both types of pili, and the fimA mutant $6 \mathrm{E} 11$ has only type IV pili (Meng et al., 2005). Under identical conditions, the fimA mutant (lacking type I pili) has a wider fringe than the Temecula parent (Li et al., 2007). When present, attachment to the substratum by type I pili may be acting as a motility 'brake' holding the cells back from more rapid motility, resulting in a narrower fringe. Attachment to various surfaces by cells with only type I pili results in more pronounced biofilm formation (Meng et al., 2005).

For any given isolate, the presence and width of the peripheral fringe was affected by the amount of BSA present in the PW medium. For the isolates that exhibited a peripheral fringe, higher BSA concentrations generally reduced or eliminated the appearance of the peripheral fringe (Figs 2 and 3). For some isolates, as well as the fimA mutant $6 \mathrm{E} 11$, a barely perceivable fringe was frequently observed at the highest BSA concentration, while medium with no BSA
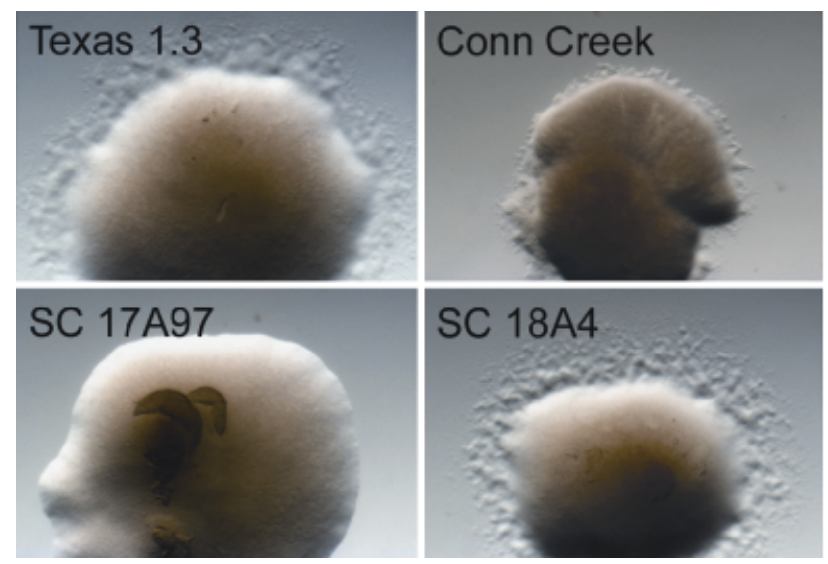
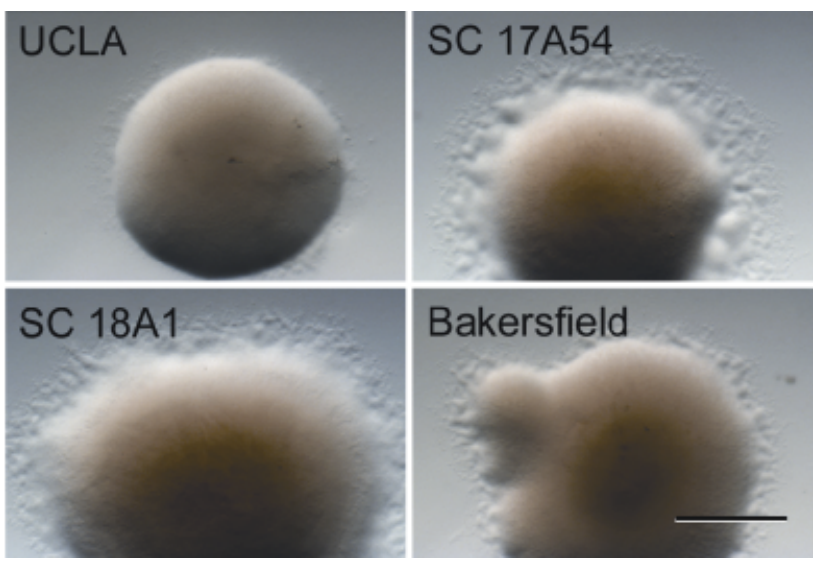

Fig. 1. Colony characteristics of eight wild-type Xylella fastidiosa isolates grown on PW agar without BSA. All isolates, except SC 17A97, exhibited a peripheral fringe, which is indicative of type IV pilus-mediated twitching motility by the bacteria. Magnification bar, $0.5 \mathrm{~mm}$. 


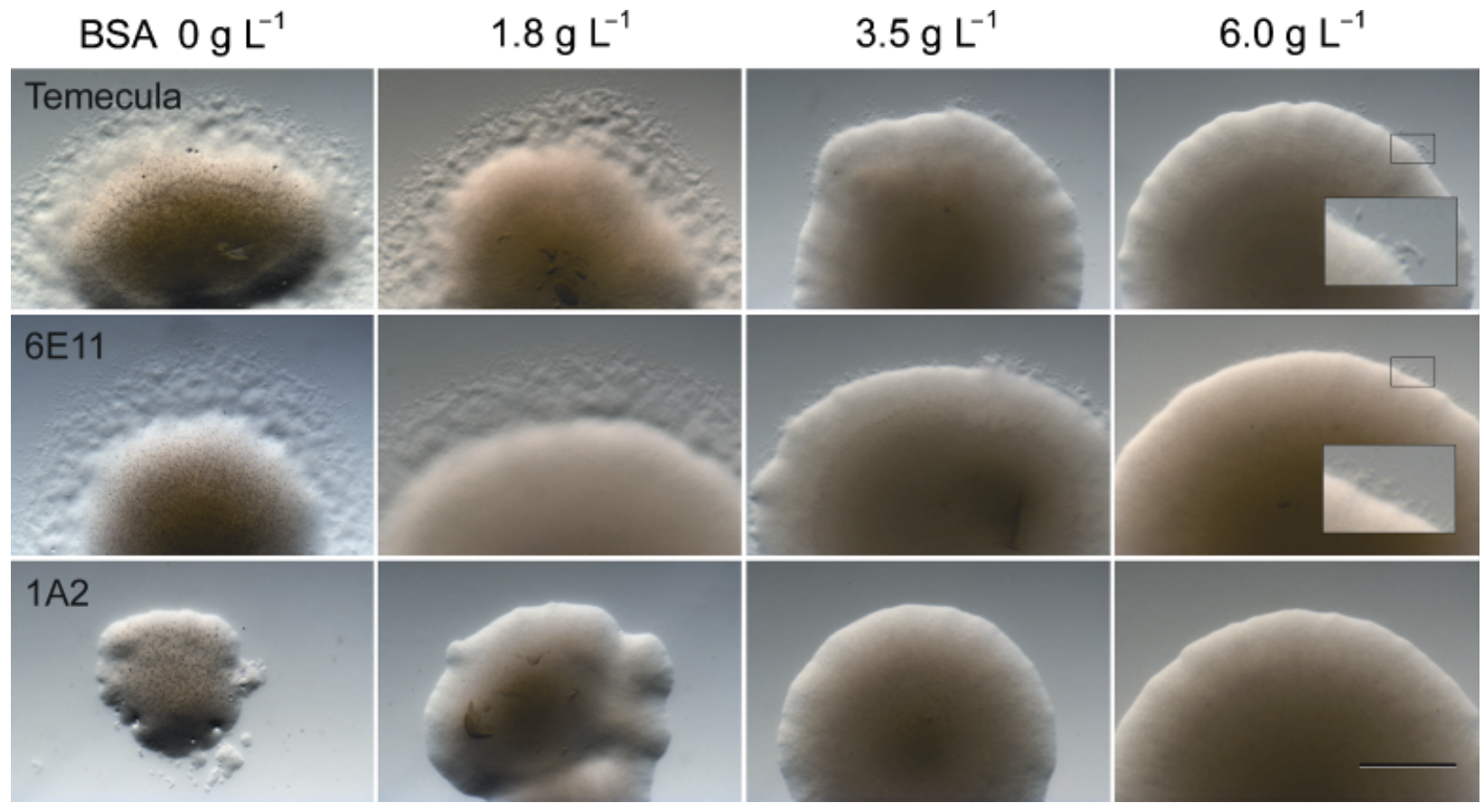

Fig. 2. Colony margin characteristics of the Temecula wild-type Xylella fastidiosa isolate and mutants $6 E 11$ and $1 A 2$ grown on PW agar with different concentrations of BSA. Inset of noted regions of Temecula and $6 \mathrm{E} 11\left(6.0 \mathrm{~g} \mathrm{~L}^{-1} \mathrm{BSA}\right)$ depicting higher magnification of colony margin. Magnification bar, $0.5 \mathrm{~mm}$.

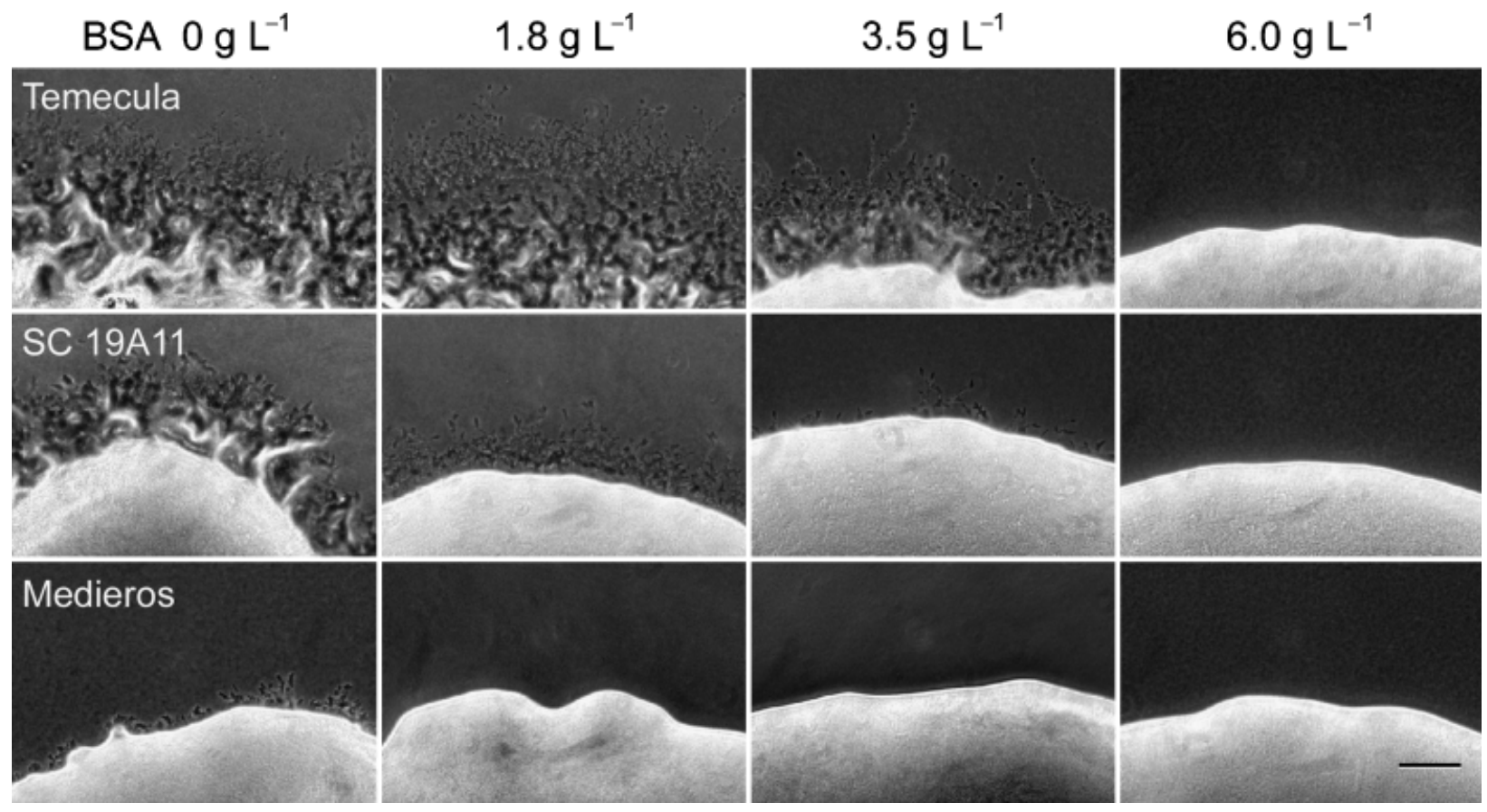

Fig. 3. Higher magnification of colony margin characteristics of the Temecula, SC 19A11, and Medieros wild-type Xylella fastidiosa isolates grown on PW agar with different concentrations of BSA. Magnification bar, $0.1 \mathrm{~mm}$.

produced the widest and most pronounced fringe (Fig. 2). At the same time, the higher BSA concentrations nearly always produced larger colonies (Fig. 2) which, in part, substantiated the original report describing the need for BSA in PW medium for X. fastidiosa (Davis et al., 1980). Furthermore, the growth of $X$. fastidiosa in PW broth containing BSA was significantly enhanced compared with PW broth without BSA (Fig. 4). 
Development of biofilm on culture vessel walls is frequently noted as a measure of bacterial adhesion to these surfaces (Marques et al., 2002). Previously, biofilm development in the wild-type Temecula isolate of $X$. fastidiosa and several mutants grown in PD2 medium without BSA had been described (Meng et al., 2005). Considering that BSA influenced peripheral fringe development in X. fastidiosa colonies on PW agar, the influence of BSA on biofilm formation in PD2 medium augmented with various concentrations of BSA was further examined. Following 8 days of growth in shaken flasks, $X$. fastidiosa developed rings of biofilm at the air-medium interface. There appeared to be little difference in the amount of biofilm among the four BSA concentrations, although the cells grown without BSA displayed slightly more biofilm. More notable was the clarity of the medium following growth; medium lacking BSA was clear, whereas medium containing $1.8,3.5$, or $6.0 \mathrm{~g} \mathrm{~L}^{-1}$ BSA was turbid. It is likely that all cells in the medium lacking BSA were either attached to the flask wall or to each other, whereas in the turbid medium containing BSA many cells were planktonic. In support of this observation, Leite et al. (2004) reported that growth in PW medium (which contains $6.0 \mathrm{~g} \mathrm{~L}^{-1}$ BSA) stimulated $X$. fastidiosa cells to be planktonic. An additional explanation for the lack of turbidity in cultures grown without BSA is that albumin

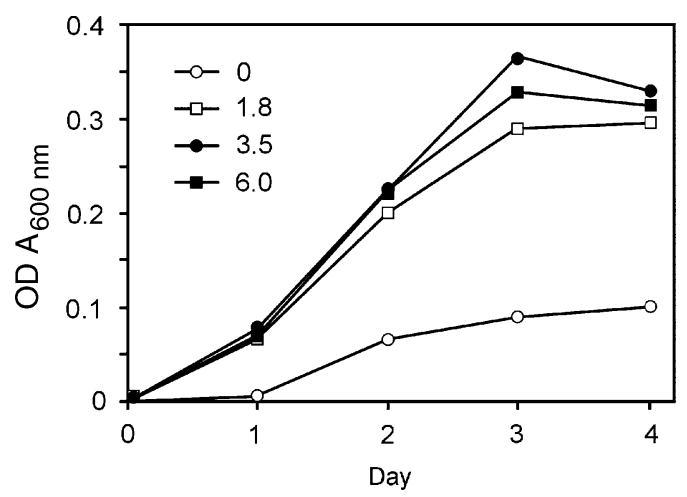

Fig. 4. Growth of Xylella fastidiosa Temecula wild-type isolate in PW medium with different concentrations of BSA. Cell density was determined at days $0,1,2,3$, and 4 by measuring $O D$ at $A_{600 \mathrm{~nm}}$. supports growth of $X$. fastidiosa. By 20 days of growth, the amount of biofilm in flasks without BSA was distinctly more than in medium with BSA (Fig. 5). It is likely that BSA coats the surface of the flask and prevents firm cell adherence, which is the initial step in biofilm formation. Cooksey et al. (2004) similarly observed decreased biofilm formation with increasing levels of BSA in PD3 medium. There is evidence in a number of other bacterial species and at least one mammalian cell line that the presence of BSA either reduced or completely eliminated cell attachment to various substrates (Burchard, 1986; Fuquay et al., 1986; Tamada \& Ikada, 1993; Al-Makhlafi et al., 1994; Cunliffe et al., 1999). BSA acts as a surfactant, thereby reducing surface tension and impeding cell attachment to a substrate (Burchard, 1986; Tamada \& Ikada, 1993; Al-Makhlafi et al., 1994; Cunliffe et al., 1999).

Until recently, there had not been evidence that $X$. fastidiosa translocated via twitching motility in vitro or in planta. When the genome sequence of X. fastidiosa was published, ORFs similar to type IV pilus genes in other bacteria were reported, and it was suggested that the pili might have a role in $X$. fastidiosa adhesion and translocation (Simpson et al., 2000; Van Sluys et al., 2003). Recently, it was shown for the first time that $X$. fastidiosa possesses two distinct types of polar pili: long, type IV pili and short, type I pili (Meng et al., 2005). Analysis of various pilus-defective mutants further demonstrated that the long, type IV pili are involved in twitching motility on an agar surface, in a microfabricated flow chamber, and in planta (Meng et al., 2005). Type IV pilus-defective mutants, e.g. $1 \mathrm{~A} 2$ ( pilB $^{-}$) did not develop a colony fringe. Mutant 6E11 is defective for the shorter type I pili $\left(\mathrm{fim}^{-}\right)$, and continued to exhibit a fringe; in fact, 6E11 usually had a wider fringe than the wild-type Temecula parent isolate. Colony morphologies of the Pierce's disease isolate of $X$. fastidiosa were first described by Wells et al. (1987) as 'smooth opalescent' and 'rough opalescent'. Subsequently, Davis et al. (1981) described colony morphologies of xylem-limited bacteria (now known to be isolates of $X$. fastidiosa) that cause phony disease of peach and plum leaf scald to be '... smooth, whereas the surface of the lesser elevated portion of the colonies was

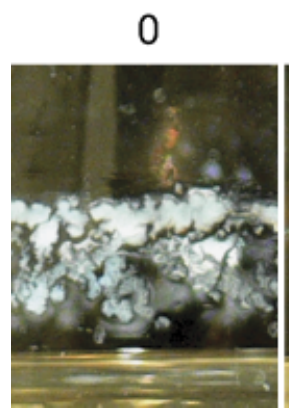

1.8

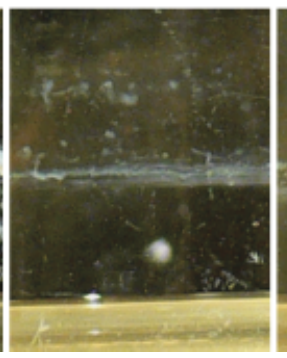

3.5

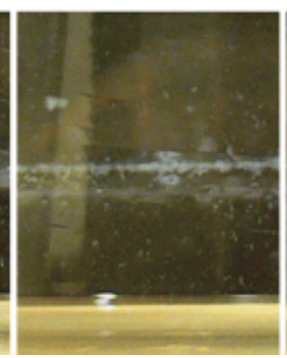

6.0

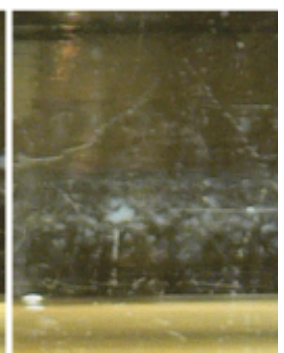

Fig. 5. Biofilm development of Xylella fastidiosa Temecula wild-type isolate following 20 days of growth in PD2 medium with different concentrations of BSA $\left(\mathrm{g} \mathrm{L}^{-1}\right)$. 
rough'. The description of 'rough' colony morphologies was interpreted as being equivalent to the peripheral fringe observed in many isolates of pathogenic X. fastidiosa, and indicative of twitching motility.

Why has the peripheral fringe not been observed more widely in X. fastidiosa cultures? The observations suggest that it is related to the BSA content of the medium, at least as far as PW medium is concerned. The original recipe for PW agar (Davis et al., 1981) included the equivalent of $6 \mathrm{~g} \mathrm{~L}^{-1}$ of BSA, the highest concentration used in the current study. Studies suggest that twitching motility is not the only type of bacterial motility inhibited by the presence of BSA (Dworkin et al., 1983; Burchard, 1986). It was demonstrated that the surfactants Tween 80 and BSA inhibited swarming and gliding motility in Cytophaga U67 (Burchard, 1986). It was suggested that inhibition of motility occurred because surfactants prevented adhesion of the bacteria to a surface. Addition of BSA to growth medium completely inhibited gliding motility of Myxococcus xanthus (Dworkin et al., 1983). In the case of twitching motility, type IV pili must attach to a surface in order for a cell to translocate via pilus retraction (Mattick, 2002). Thus, in the presence of BSA or other surfactants, type IV pilus-mediated motility will not occur. Interestingly, there is evidence that BSA stimulates twitching in Pseudomonas aeruginosa (Huang et al., 2003), and if that were true for X. fastidiosa as well, the peripheral fringe would have been expected to be enhanced with increasing BSA concentrations, which was not observed.

In bacteria of the genera Rochalimaea (formerly Rickettsia) (Myers et al., 1969), Neisseria (Glass \& Kennett, 1939; Mueller \& Hinton, 1941), and Bordetella (Mishulow et al., 1953; Wilson, 1963), it was reported that substances such as activated charcoal or starch can be substituted for serum; therefore, BSA is likely not serving a specific nutritive role in bacterial growth. The fact that charcoal or starch can replace serum suggests that the role of BSA may be nonspecific; serum may 'detoxify' growth media by sequestering growthinhibiting substances. BSA is not essential for growth in $X$. fastidiosa; however, growth is slower in its absence (Fig. 2) (Davis et al., 1980).

In X. fastidiosa, biofilm formation is inhibited by the presence of BSA in the medium, and there is a direct relationship between increasing BSA concentration and a reduction in biofilm formation (Cooksey et al., 2004). It is likely that the surfactant quality of BSA imparts a coating on surfaces that impedes bacterial cell or pilus attachment, and therefore biofilm formation. Biofilm development begins with the attachment of a single layer of cells to a substrate, which is followed by the attachment of additional layers of cells and the production of exopolysaccharide. If the initial step of cell attachment is prevented by BSA, then biofilm will not be produced.
Importantly, it was demonstrated that the Pierce's disease Temecula isolate of $X$. fastidiosa is not unique with respect to twitching motility and colony fringe development. All pathogenic isolates from California, South Carolina, and Texas, except SC 17A97, exhibited these properties on PW agar. When examined in greater detail, isolate SC 17A97 cells also exhibited twitching motility; thus, it is likely that most other X. fastidiosa isolates will have this phenotype. The data show that the concentration of BSA in PW agar dramatically influenced the appearance of the peripheral fringe. At the concentration of BSA used in the original $\mathrm{PW}$ recipe (Davis et al., 1981), the peripheral fringe of the bacterial colonies is either greatly reduced or absent. Although BSA is not a natural component of xylem fluid, the results suggest the crucial role that grape xylem wall surface chemistry likely plays in the initial attachment of $X$. fastidiosa cells to the xylem, and the subsequent progression of Pierce's disease. An examination of xylem fluid composition in resistant vs. susceptible plants may help us to better predict strategies for controlling this pathogen.

\section{Acknowledgements}

Funding for this project was supported, in part, by the University of California Pierce's Disease Grant Program. We thank D. Appel, C.J. Chang, A. Purcell, and S. Lindow for providing various isolates, and M.J. Davis for helpful discussions. We also thank Leonardo De La Fuente for helpful advice and for critically reviewing the manuscript.

\section{References}

Al-Makhlafi H, McGuire J \& Daeschel M (1994) Influence of preadsorbed milk proteins on adhesion of Listeria monocytogenes to hydrophobic and hydrophilic silica surfaces. Appl Environ Microbiol 60: 3560-3565.

Bradley DE (1980) A function of Pseudomonas aeruginosa PAO polar pili: twitching motility. Can J Microbiol 26: 146-154.

Burchard RP (1986) The effect of surfactants on the motility and adhesion of gliding bacteria. Arch Microbiol 146: 147-150.

Cooksey DA, Dumenyo K \& Hernandez-Martinez R (2004) DNA microarray and mutational analysis to identify virulence genes in Xylella fastidiosa. In Proceedings of the Pierce's Disease Research Symposium, San Diego, CA. 174-177.

Cunliffe D, Smart CA, Alexander C \& Vulfson EN (1999) Bacterial adhesion at synthetic surfaces. Appl Environ Microbiol 65: 4995-5002.

Davis MJ, Purcell AH \& Thompson SV (1980) Isolation media for the Pierce's disease bacterium. Phytopathol 70: 425-429.

Davis MJ, French WJ \& Schaad NW (1981) Axenic culture of the bacteria associated with phony disease of peach and plum leaf scald. Curr Microbiol 6: 309-314.

de Souza AA, Takita MA, Coletta-Filho HD, Caldana C, Goldman GH, Yanai GM, Muto NH, de Oliveira RC, Nunes LR \& 
Machado MA (2003) Analysis of gene expression in two growth states of Xylella fastidiosa and its relationship with pathogenicity. Mol Plant-Microbe Interact 16: 867-875.

Dworkin M, Keller KH \& Weisberg D (1983) Experimental observations consistent with a surface tension model of gliding motility of Myxococcus xanthus. J Bacteriol 155: 1367-1371.

Fuquay JI, Loo DT \& Barnes DW (1986) Binding of Staphylococcus aureus by human serum spreading factor in an in vitro assay. Infect Immunol 52: 714-717.

Glass V \& Kennett SJ (1939) The effect of various forms of particulate carbon on the growth of the gonococcus and meningococcus. J Pathol Bacteriol 49: 125-133.

Glessner A, Smith RS, Iglewski BH \& Robinson JB (1999) Roles of Pseudomonas aeruginosa las and rhl quorum-sensing systems in control of twitching motility. J Bacteriol 181: 1623-1629.

Hendson M, Purcell AH, Chen D, Smart C, Guilhabert M \& Kirkpatrick B (2001) Genetic diversity of Pierce's disease strains and other pathotypes of Xylella fastidiosa. Appl Environ Microbiol 67: 895-903.

Hopkins DL (1985) Physiological and pathological characteristics of virulent and avirulent strains of the bacterium that causes Pierce's disease of grapevine. Phytopathol 75: 713-717.

Huang B, Whitchurch CB \& Mattick JS (2003) FimX, a multidomain protein connecting environmental signals to twitching motility in Pseudomonas aeuruginosa. J Bacteriol 185: 7068-7076.

Leite B, Andersen PC \& Ishida ML (2004) Colony aggregation and biofilm formation in xylem chemistry-based media for Xylella fastidiosa. FEMS Microbiol Lett 230: 283-290.

Li Y, Hao G, Galvani CD, Meng Y, De La Fuente L, Hoch HC \& Burr TJ (2007) Type I and type II pili of Xylella fastidiosa affect twitching motility, biofilm formation, and cell-wall aggregation. Microbiol, in press.

Liu HL, Kang YW, Genin S, Schell MA \& Denny TP (2001) Twitching motility of Ralstonia solanacearum requires a type IV pilus system. Microbiol 147: 3215-3229.

Marques LLR, Ceri H, Manfio GP, Reid DM \& Olson ME (2002) Characterization of biofilm formation by Xylella fastidiosa in vitro. Plant Dis 86: 633-638.
Mattick JS (2002) Type IV pili and twitching motility. Annu Rev Microbiol 56: 289-314.

Meng Y, Li Y, Galvani CD, Turner JN, Burr TJ \& Hoch HC (2005) Upstream migration of Xylella fastidiosa via pilus-driven twitching motility. J Bacteriol 187: 5560-5567.

Mishulow L, Sharpe LS \& Cohen LL (1953) Beef heart charcoal agar for the preparation of pertussis vaccines. Am J Pub Health 43: 1466-1472.

Mueller JH \& Hinton J (1941) A protein-free medium for primary isolation of the gonococcus and meningococcus. Proc Soc Exptl Biol Med 48: 330-333.

Myers WF, Cutler LD \& Wisseman CL Jr (1969) Role of erythrocytes and serum in the nutrition of Rickettsia quintana. J Bacteriol 97: 663-666.

Purcell AH \& Hopkins DL (1996) Fastidious xylem-limited bacterial plant pathogens. Annu Rev Phytopathol 34: 131-151.

Semmler AB, Whitchurch CB \& Mattick JS (1999) A reexamination of twitching motility in Pseudomonas aeruginosa. Microbiol 145: 2863-2873.

Simpson AJG, Reinach FC, Arruda P et al. (2000) The genome sequence of the plant pathogen Xylella fastidiosa. Nature 406: 151-157.

Tamada Y \& Ikada Y (1993) Effect of preadsorbed proteins on cell adhesion to polymer surfaces. J Colloid Interface Sci 155: 334-339.

Van Sluys MA, de Oliveira MC, Monteiro-Vitorello CB et al. (2003) Comparative analyses of the complete genome sequences of Pierce's disease and citrus variegated chlorosis strains of Xylella fastidiosa. J Bacteriol 185: 1018-1026.

Wells JM, Raju BC, Hung H-Y, Weisburg WG, Mandelco-Paul L \& Brenner DJ (1987) Xylella fastidiosa gen. nov., sp. nov.: gram-negative, xylem-limited, fastidious plant bacteria related to Xanthomonas spp. Int J Syst Bacteriol 37: 136-143.

Wilson RJ (1963) Cultivation of Bordetella pertussis (phase 1) in a chemically defined medium. Can J Pub Health 54: 518-523. 